\title{
Prevalence and pattern of menstrual disorders among Lebanese nursing students
}

\author{
N. Karout, ${ }^{7}$ S.M. Hawai ${ }^{2}$ and S. Altuwaijri ${ }^{2}$
}

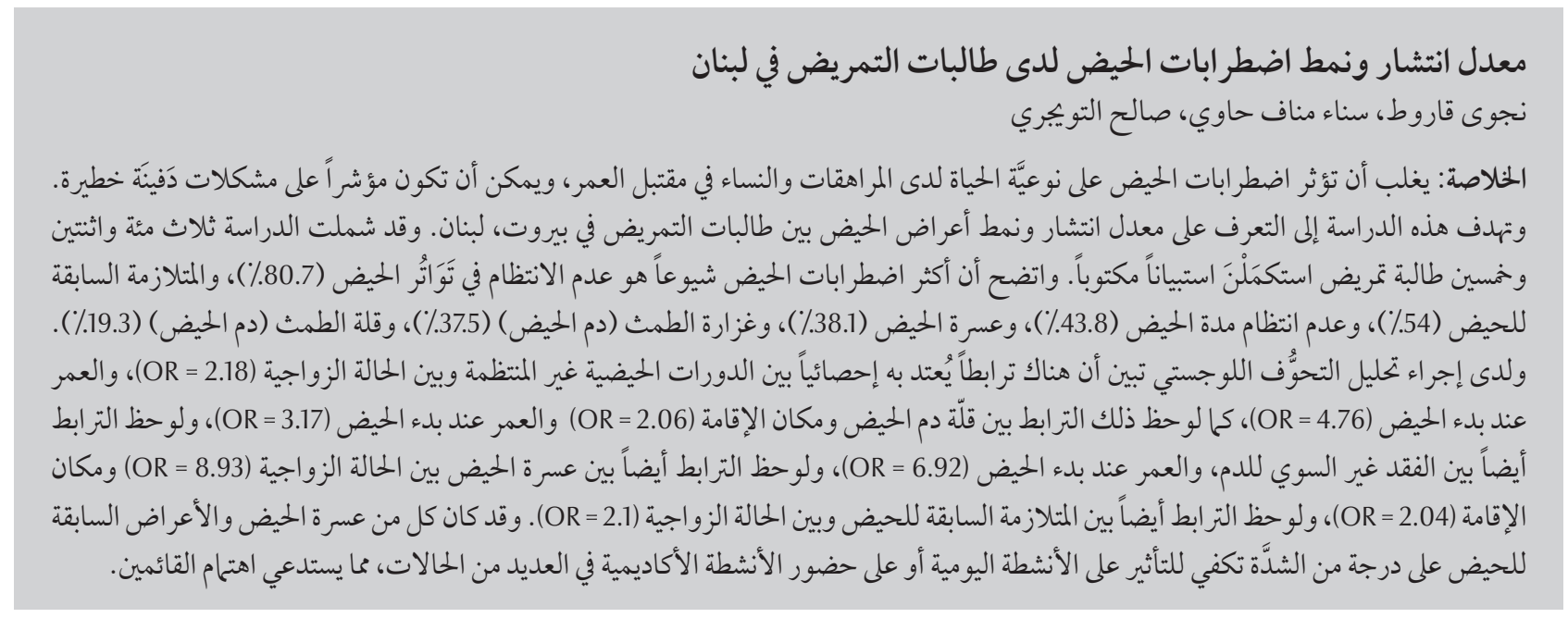

ABSTRACT Menstrual disorders frequently affect the quality of life of adolescents and young adult women and can be indicators of serious underlying problems. The objective of this study was to determine the prevalence and pattern of menstrual symptoms among nursing students in Beirut, Lebanon. Of 352 students completing a written questionnaire, the most common menstrual disorders were irregular frequency of menstruation (80.7\%), premenstrual syndrome (54.0\%), irregular duration of menstruation (43.8\%), dysmenorrhoea (38.1\%), polymenorrhoea (37.5\%) and oligomenorrhoea (19.3\%). On logistic regression analysis, there were significant associations between irregular cycles and marital status (OR 2.18) and menarcheal age (OR 4.76); oligomenorrhoea and residency (OR 2.06) and menarcheal age (OR 3.17); abnormal blood loss and menarcheal age (OR 6.92); dysmenorrhoea and marital status (OR 8.93) and residency (OR 2.04); and premenstrual syndrome and marital status (OR 2.10). Dysmenorrhoea and premenstrual symptoms were serious enough to affect daily activities or academic attendance in many cases and this is a concern for policy-makers.

\section{Prévalence et caractéristiques des troubles menstruels chez des élèves infirmières libanaises}

RÉSUMÉ Les troubles menstruels affectent fréquemment la qualité de vie des adolescentes et des jeunes femmes et peuvent être des indicateurs de troubles sous-jacents graves. La présente étude visait à déterminer la prévalence et les caractéristiques des symptômes menstruels chez des élèves infirmières à Beyrouth (Liban). Les troubles menstruels les plus fréquents observés chez les 352 élèves ayant rempli un questionnaire étaient l'irrégularité des cycles menstruels $(80,7 \%)$, un syndrome prémenstruel (54,0\%), une durée irrégulière des menstruations (43,8 \%), une dysménorrhée (38,1\%), une polyménorrhée (37,5\%) et une oligoménorrhée (19,3\%). L'analyse de régression logistique a révélé l'existence d'associations significatives entre l'irrégularité des cycles, la situation matrimoniale (O.R. 2,18) et l'âge des premières menstruations (O.R. 4,76) ; entre une oligoménorrhée, le lieu de résidence (O.R. 2,06) et l'âge des premières menstruations (O.R. 3,17) ; entre des saignements anormaux et l'âge des premières menstruations (O.R. 6,92); entre une dysménorrhée, la situation matrimoniale (O.R. 8,93) et le lieu de résidence (O.R. 2,04); et entre un syndrome prémenstruel et la situation matrimoniale (O.R. 2,10). Dans de nombreux cas, les dysménorrhées et les symptômes prémenstruels étaient suffisamment intenses pour influer sur les activités quotidiennes ou l'assiduité aux cours. Cette situation est préoccupante pour les responsables de l'élaboration des politiques.

${ }^{7}$ Saad College of Nursing and Allied Health Sciences, Al-Khobar, Saudi Arabia (Correspondence to N. Karout: nkarout@yahoo.com). ${ }^{2}$ Saad Research and Development Centre, Saad Specialist Hospital, Al-Khobar, Saudi Arabia.

Received: 22/09/11; accepted: 25/09/11 


\section{Introduction}

Menstrual disorders frequently affect the quality of life of adolescents and young adult women, especially those who suffer dysmenorrhoea and heavy menstruation [1]. The World Health Organization reports that 18 million women aged $30-55$ years perceive their menstrual bleeding to be excessive [2]. Such disorders also have economic consequences in terms of health care costs due to the consumption of expensive hormonal drugs and laboratory tests $[3,4]$. As well as health problems there can be consequences such as limitations on attendance at work and school which hinder academic achievements and employment prospects [5].

Menstrual disorders include menstrual cycle irregularities (of duration or length), hyper- or hypomenorrhoea, poly- or oligomenorrhoea, dysmenorrhoea, amenorrhoea, menorrhagia and premenstrual syndrome (PMS) [6]. Previous studies have shown a high prevalence of dysmenorrhoea and menstrual irregularity among female students ( $73 \%$ and $65 \%$ respectively) and that these problems affected the women's social activities and school attendance $[3,5]$. Another study showed that the prevalence of no, mild, moderate and severe menstrual pain among Iranian women was $10 \%, 41 \%, 28 \%$ and $22 \%$ respectively [7]. A high proportion of women in other studies reported suffering oligomenorrhoea or amenorrhoea and these have been associated with body mass index (BMI) and other complications such as polycystic ovary syndrome (PCOS), hirsutism or infertility [8-10]. Menstrual disorders have multiple etiologies [11] and studies of associated variables have found relationships with diet and eating disorders [12-14], exercise and BMI $[11,15,16]$, stress $[17,18]$ and chronic diseases [19-23].

The objectives of this study were to determine the prevalence and pattern of menstrual symptoms among nursing students in Lebanon and to study some of the correlates of menstrual disorders.

\section{Methods}

\section{Sample}

We carried out a cross-sectional study of Lebanese nursing students who attended the Islamic University of Lebanon in Beirut during the academic year 2005-06. The students of this college came from all regions and different socioeconomic strata of Lebanon. Based on a prevalence of $25 \%$ of women having menstrual disorders (the lowest recorded prevalence [6]) and with 5\% error and 95\% confidence interval the minimum sample size was estimated as 300 using Epi-info, version 6 . To allow for non-responses all 420 female students registered in the academic year 2005-06 in all years of study were selected.

\section{Data collection}

A self-administered, structured, anonymous questionnaire covering 21 items was designed for the study. The researcher reviewed the tools used in previous studies to prepare the questionnaire, then a pilot study was conducted with 10 female students randomly selected from all academic years of the nutrition section of the health department. The pilot questionnaires were distributed twice to the same students at a 10-day interval and then the data were analysed to determine the test-retest reliability.

Data were collected over a 3-day period in February 2006. In cooperation with the university authorities and according to the students' academic schedule the questionnaire was distributed to the nursing students in their class. The questionnaire was delivered in English or French depending on the language of the course and took about 30-45 minutes to complete. The purpose and the objectives of the study were explained by the female researchers and students were informed that participation was optional. It was emphasized that all data collected were strictly confidential and students were requested to sign the consent form attached to the questionnaire.

The questionnaire covered information about the following demographic variables: age, marital status, residence and presence of pregnancy and breastfeeding (to rule out the cause of amenorrhoea if present) these questions were closed-ended. The participants were then asked about the characteristics of their menstruation: age of menarche (open question); regularity/irregularity of menstruation in interval and duration; presence of amenorrhoea (secondary); amount of blood loss (number of pads used); pain during menstruation and degree and location of pain; activity during menstruation; symptoms of PMS, whether the symptoms disappear after menstruation and the affect of PMS on activities of life (close-ended questions). Menstrual disorders were defined as follows [6,24-26]:

- Secondary amenorrhoea: no period during the last 3 months.

- Regular menstruation: cycle repeated about once every 28-32 days with duration 5-7 days.

- Oligomenorrhoea: cycle monthly repeated about once every $>32$ days.

- Polymenorrhoea: cycle repeated about once every $\leq 21$ days.

- Hypomenorrhoea: duration of period $<3$ days and slight blood loss (using $<1 \mathrm{pad}$ ).

- Hypermenorrhoea: duration of period $>7$ days and blood loss $>80 \mathrm{~mL}$ (using $\geq 5$ pads)

- Dysmenorrhoea: painful menstruation (mild, moderate or severe).

- PMS: at least 3 of the most common symptoms occurring 10 days before menstruation and disappearing at the start of menstruation: painful or tender breasts, bloating or swelling of the abdomen, rapid mood changes, depressed mood or other (open question). 


\section{Data analysis}

Data were analysed using SPSS, version 8. Frequencies and percentages are presented or mean and standard deviation (SD) as appropriate. Bivariate analysis of data was done and the chi-squared test of significance was done where appropriate. $P<0.05$ was considered statistically significant. Logistic regression analysis was performed to investigate factors associated with menstrual disorders

\section{Results}

\section{Background characteristics}

Of the 420 nursing students recruited for the study, 352 (83.8\%) completed the questionnaire. Table 1 shows the background characteristics of the sample. The mean age was 20.9 (SD 1.8) years, range $18-26$ years. Two were pregnant and 4 were breastfeeding during data collection.
The reported age of onset of menstruation was $<12$ years old for $17.0 \%$ of students, 13 years for $33.6 \%$, 14 years for $26.1 \%$ and $>14$ years for $23.3 \%$. The mean menarcheal age was 13.2 (SD 1.4) years.

\section{Prevalence of menstrual disorders}

Overall $284(80.7 \%)$ of the students reported suffering from one or more types of menstrual dysfunction (Table 2 ). The most common problem was irregular frequency; $53.5 \%$ of students always and 5.9\% sometimes experienced this. Oligomenorrhoea with irregular cycles was reported usually or sometimes by $10.5 \%$ and $14.7 \%$ of students respectively, and polymenorrhoea with irregular cycles was experienced usually or sometimes by $7.6 \%$ and $43.8 \%$ of students respectively. Some women with regular cycles also reported oligomenorrhoea and polymenorrhoea.
A small proportion of students (2.0\%) reported hypomenorrhoea, i.e. duration of menstruation usually $<3$ days, and $11.6 \%$ experienced hypermenorrhoea, i.e. duration usually $>7$ days. According to the number of pads used during a cycle $2.0 \%$ of women reported very light menstruation $(<1$ pad daily) and $11.7 \%$ had heavy bleeding ( $\geq$ 5 pads daily).

A high proportion of the women suffered from dysmenorrhoea (63.1\%) and $54.0 \%$ reported having 3 of the signs of PMS

Table 2 also shows that $5.1 \%$ of women had secondary amenorrhoea and $3.2 \%$ did not know if they had had any menstruation during the previous 3 months.

Of the students experiencing dysmenorrhoea, $19.3 \%$ suffered a mild degree of pain, $20.2 \%$ moderate and $60.3 \%$ severe (Table 3 ). Most of them

\begin{tabular}{|c|c|c|c|c|c|c|c|c|}
\hline \multirow[t]{3}{*}{ Variable } & \multirow[t]{3}{*}{ No. } & \multirow[t]{3}{*}{$\%$} & \multicolumn{6}{|c|}{ Association with: } \\
\hline & & & \multicolumn{2}{|c|}{ Irregular cycles } & \multicolumn{2}{|c|}{ Premenstrual syndrome } & \multicolumn{2}{|c|}{ Dysmenorrhoea } \\
\hline & & & $x^{2}$ & $P$-value & $x^{2}$ & $P$-value & $x^{2}$ & $P$-value \\
\hline \multicolumn{9}{|l|}{ Age (years) } \\
\hline $18-20$ & 161 & 45.7 & 276 & $<0.001$ & 197 & $<0.001$ & 161 & $<0.001$ \\
\hline $21-23$ & 175 & 49.7 & & & & & & \\
\hline $24-26$ & 16 & 4.6 & & & & & & \\
\hline Residency & & & 8.6 & 0.03 & 17.6 & $<0.001$ & 13.0 & $<0.001$ \\
\hline Dormitory & 90 & 25.6 & & & & & & \\
\hline $\begin{array}{l}\text { With family (husband } \\
\text { or parents) }\end{array}$ & 262 & 74.4 & & & & & & \\
\hline Marital status & & & 20.7 & $<0.001$ & 8.3 & 0.5 & 46.1 & $<0.001$ \\
\hline Single & 306 & 86.9 & & & & & & \\
\hline Married & 42 & 11.9 & & & & & & \\
\hline Other & 4 & 1.2 & & & & & & \\
\hline No. of children & & & 19.1 & $<0.001$ & 2.2 & 0.9 & 3.6 & 0.7 \\
\hline 0 & 346 & 98.3 & & & & & & \\
\hline 1 & 5 & 1.4 & & & & & & \\
\hline 2 & 1 & 0.3 & & & & & & \\
\hline \multicolumn{9}{|l|}{ Menarcheal age (years) } \\
\hline$<12$ & 60 & 17.0 & 270 & $<0.001$ & 124 & $<0.001$ & 161 & $<0.001$ \\
\hline 12 & 75 & 21.3 & & & & & & \\
\hline 13 & 43 & 12.3 & & & & & & \\
\hline 14 & 92 & 26.1 & & & & & & \\
\hline$>14$ & 82 & 23.3 & & & & & & \\
\hline
\end{tabular}


Table 2 Prevalence of menstrual disorders among the sample of nursing students $(n=352)$ and association with premenstrual syndrome

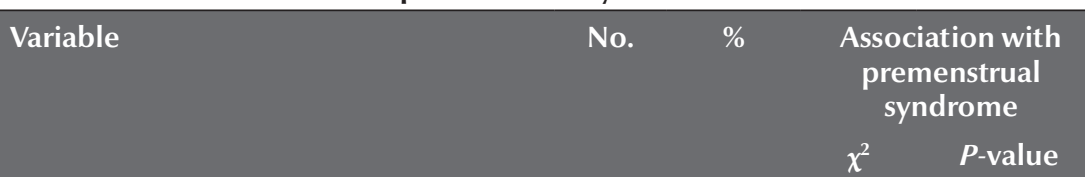

\section{Secondary amenorrhea}

Yes

Don't know

Irregular cycles

No

Rarely

Sometimes

Yes

\section{Oligomenorrhoea}

With irregular cycles $(n=210)$

Yes

Sometimes

Rarely

With regular cycles $(n=143)$

Yes

Sometimes

Rarely

\section{Polymenorrhoea}

With irregular cycles $(n=210)$

Yes

Sometimes

Rarely

With regular cycles $(n=143)$

Yes

Sometimes

Rarely

Duration of menstruation (days)

$<3$ (hypomenorrhoea)

3-7 (normal)

$>7$ (hypermenorrhoea)

Amount of blood loss (no. of pads daily)

$<1$

$1-$

3-

$\geq 5$

\section{Dysmenorrhoea}

Yes

No

Premenstrual syndrome ${ }^{a}$

Yes

No
18

323

5.1

91.7

3.2

50.2

$<0.001$

$123 \quad 34.8$

$20 \quad 5.7$

$21 \quad 5.9$

189

53.5

$87.8<0.001$

86.4

11.6

16.9

0.65

$\begin{array}{ll}7 & 2.0\end{array}$

$95 \quad 27.0$

$209 \quad 59.4$

aPainful or tender breasts, bloating or swelling of abdomen, rapid mood change, depressed mood or other (nausea, weakness, agitation, light-headedness, bloating, low back pain, fatigue). $n / a=$ not applicable. reported abdominal pain that extended to the thighs. A great majority reported that the pain affected their daily activities usually or sometimes $(59.4 \%$ and $33.3 \%$ respectively) and many had been absent from the classes because of pain usually or sometimes $(8.5 \%$ and $39.6 \%$ respectively).

Of those who suffered from PMS, $97.8 \%$ reported that the signs usually disappeared with the beginning of menstruation and $60.0 \%$ and $31.5 \%$ reported that the symptoms usually and sometimes reduced their daily activity respectively (Table 4 ).

\section{Correlates of menstrual disorders}

Table 1 shows that a significant relationship was found between the independent variables age, residency and menarcheal age and the dependant variables PMS, dysmenorrhoeal and regularity of menstruation $($ all $P<0.001)$. There was also a significant relationship between marital status and both regular menstruation and dysmenorrhoea (both $P<0.001$ ) but not with PMS $(P=0.5)$. There was no significant relationship between the number of children the woman had and either PMS or dysmenorrhoea $(P=0.9$ and $P=0.7$ respectively), but there was a significant relationship with regularity of cycles $(P<0.001)$.

Table 2 shows that there was a significant relationship between the presence of PMS and having regular cycles, oligomenorrhoea, polymenorrhoea, duration of period and dysmenorrhoea (all $P<0.001$ ), but there was no relationship between PMS and presence of amenorrhoea or amount of blood loss ( $P=0.5$ and $P=0.6$ respectively).

On logistic regression analysis, there were significant associations between irregular cycles and marital status (OR 2.18) and menarcheal age (OR 4.76); oligomenorrhoea and residency (OR 2.06) and menarcheal age (OR 3.17); abnormal blood loss and menarcheal age (OR 6.92); dysmenorrhoea and marital status (OR 8.93) and residency (OR 2.04); PMS and marital status (OR 2.10) (Table 5) 


\begin{tabular}{lrr}
\hline $\begin{array}{l}\text { Table } 3 \text { Experience of symptoms among nursing students suffering from } \\
\text { dysmenorrhoea ( } \boldsymbol{n}=\mathbf{2 2 2})\end{array}$ & No. & $\%$ \\
\hline Variable & 43 & 19.3 \\
Severity of pain & 45 & 20.2 \\
Mild & 134 & 60.3 \\
Moderate & & \\
Severe & 45 & 20.2 \\
Location of pain & 12 & 5.4 \\
Abdominal pain & 136 & 1.2 \\
Back pain & 21 & 9.4 \\
Abdominal pain extends sometimes to the thighs & 8 & 3.6 \\
Back pain extends sometimes to the anus & & \\
Other (abdominal pain extends to the thighs and anus) & 132 & 59.4 \\
Symptoms reduce productivity in daily activities & 74 & 33.3 \\
Usually & 8 & 3.6 \\
Sometimes & & \\
Never & 19 & 8.5 \\
Ever been absent from classes & 88 & 39.6 \\
Usually & 10 & 4.5 \\
Sometimes & &
\end{tabular}

\begin{tabular}{lcc}
\hline $\begin{array}{l}\text { Table 4 Experience of symptoms among nursing students suffering from } \\
\text { premenstrual syndrome }(\boldsymbol{n}=\mathbf{1 9 0})\end{array}$ & No. & $\%$ \\
\hline Variable & 6 & 3.1 \\
Associated symptoms & 13 & 6.8 \\
$\quad$ Painful or tender breasts & 9 & 4.7 \\
Bloating or swelling of abdomen & 5 & 2.6 \\
Rapid mood changes & 189 & 99.4 \\
Depressed mood & & \\
(3 out of 4 symptoms) & 186 & 97.8 \\
Symptoms disappear with menstruation & 4 & 2.1 \\
Usually & 0 & 0.0 \\
Sometimes & & \\
Never & 114 & 60.0 \\
Symptoms reduce productivity in daily activities & 60 & 31.5 \\
Usually & 16 & 8.4 \\
Sometimes &
\end{tabular}

\section{Discussion}

Menstrual dysfunction is a common cause of referral to the gynaecology clinic and the problem has a considerable impact on the health status and the quality of life of women [27]. Menstrual disorders and the private nature of the data related to menstruation, however, symptoms were serious enough to affect their daily activities or academic attendance in many cases. In a study in Morocco, menstrual pain was often cited as the main single cause of school absenteeism among adolescent girls [30]. Also numerous studies have indicated that a considerable proportion of women of reproductive age suffer from mensesassociated health problems, such as premenstrual symptoms, dysmenorrhoea and irregular menstrual cycles [31-35]. Another study reported that $75 \%$ of girls experience some problems associated with menstruation [36] and in a study among female prisoners 33\% reported menstrual irregularity [37]

From those who suffered from dysmenorrhoea in our study, $60.3 \%$ reported the severity of pain as severe, $20.2 \%$ as moderate and only $19.3 \%$ as mild. In a study in India the prevalence of dysmenorrhoea was $51 \%$ but only $15 \%$ of adolescents with dysmenorrhoea reported their pain as severe [38]. In Egypt too $75 \%$ of female secondaryschool students experienced dysmenorrhoea while $14.8 \%$ described it as severe. These differences in the degree of pain severity may be related to cultural differences in pain perception and variability in pain threshold. In our study $13.0 \%$ of students suffered from dysmenorrhoea that extended to the anus, which may be an indicator of endometriosis [39]. Endometriosis also needs to be detected early and treated, especially before a woman becomes pregnant.

In the present study $25.2 \%$ of the students with irregular menstruation had oligomenorrhoea, which may be a symptom of PCOS; previous research has reported that $50 \%$ of women who had irregular periods had PCOS [19]. Irregular menstruation has been associated with increases in the rate of coronary heart disease and diabetes type 2 [20]. Irregularity and oligomenorrhoea are also factors that increase the rate of psychological diseases such as anxiety [40].

Around half of the students in our study (51.4\%) reported polymenorrhoea. 


\begin{tabular}{|c|c|c|c|c|c|c|}
\hline \multirow[t]{2}{*}{ Variable } & \multicolumn{3}{|c|}{ Marital status } & \multicolumn{3}{|c|}{ Residency } \\
\hline & B & $P$-value & OR $(95 \% \mathrm{Cl})$ & B & $P$-value & OR $(95 \% \mathrm{Cl})$ \\
\hline Irregular menstruation & 0.78 & 0.02 & $2.18(1.14-4.16)$ & -0.186 & 0.45 & $0.83(0.51-1.34)$ \\
\hline Oligomenorrhoea & -0.35 & 0.35 & $0.71(0.34-1.50)$ & 0.722 & 0.01 & $2.06(1.18-3.60)$ \\
\hline Polymenorrhoea & 0.61 & 0.61 & $0.55(0.29-1.03)$ & -0.144 & 0.57 & $0.87(0.53-1.42)$ \\
\hline Hypo- or hypermenorrhoea & -0.208 & 0.57 & $0.81(0.40-1.66)$ & -0.82 & 0.78 & $0.92(0.52-1.63)$ \\
\hline Abnormal amount of blood loss & 0.48 & 0.17 & $1.62(0.82-3.20)$ & 1.71 & 0.009 & $2.04(0.92-2.40)$ \\
\hline Dysmenorrhoea & 2.19 & 0.001 & $8.93(4.14-19.3)$ & 1.74 & 0.009 & $2.04(1.20-3.48)$ \\
\hline Premenstrual syndrome & 0.74 & 0.02 & $2.10(1.11-3.92)$ & -0.635 & 0.01 & $0.53(0.33-0.86)$ \\
\hline
\end{tabular}

$O R=$ odds ratio; $C l=$ confidence interval.

This is concerning as previous studies showed that menstrual blood loss affects women's quality of life and that heavy bleeding can put women at risk of anaemia $[5,23,27,41]$.

Three or more symptoms of PMS (breast tenderness, abdominal bloating or swelling, rapid mood changes and depressed mood) were reported by $54.0 \%$ of our students, which is slightly lower than a study in India which reported the prevalence of PMS as 67\% [38]. Various biosocial and psychological causes for the syndrome have been proposed, including abnormal serotonin function, presence of progesterone, altered endorphin modulation of gonodotrophin secretion, exercise habits, smoking, use of alcohol, altered transcapillary fluid balance and a diet rich in beef or caffeine containing beverages [42]. In our study $60 \%$ of the students reported that PMS affected their daily activities and $31.5 \%$ that it sometimes affected them. Similar studies among female high school adolescents showed that a majority identified dysmenorrhoea and PMS as problems that significantly affected their academic performance $[31,32,38]$.
The results of this study showed that there was a relationship between PMS and abnormal age of menarche and irregular menstruation and also with dysmenorrhoea.

In logistic regression the odds of having irregular menstruation among nursing students that had abnormal menarcheal age $(<12$ years and $>14$ years) was 4.76 times that of those having normal menarcheal age. There were also a 3.17 higher risk of oligomenorrhoea and 6.92 higher risk of abnormal blood loss during their period. Other studies showed that age of menarche < 11 years and $>14$ years were associated with a higher prevalence of menstrual disorders [11,20].

In our study $86.9 \%$ of the women were single and $25.6 \%$ lived alone in dormitories and there were a significant relationship between residency and PMS and dysmenorrhoea. In logistic regression the odds of having dysmenorrhoea was 8.93 times higher among single students than those who were married and 2.04 times higher among students who lived in a dormitory than those who lived with their family. There were also significant relationships between marital status and regular menstruation (OR 2.18) and dysmenorrhoea (OR 8.93). Previous studies showed a relationship between marital status and menstrual disorders $[1,5,11]$. The reasons why certain kinds of lifestyle and being married reduces the prevalence of menstrual disorders are unclear but previous researchers have suggested that stress has an effect on menstrual disorders $[17,18]$. Previous studies also showed that socioeconomic status and living alone in a new environment under stress was associated with menstrual disorders $[17,18,20,28,36]$.

In summary, this study found a high percentage of different menstrual disorders among young female students in Lebanon. These disorders are not only likely to affect the quality of life and future productivity of women but may also be indicators of underlying problems that can become serious in the future and this is an important concern for reproductive health policy-makers. Health education on menstrual problems targeting female students and their parents, and including education on reproductive health in the school curriculum may assist in early detection of these disorders.

\section{References}

1. Cakir M et al. Okten, A Menstrual pattern and common menstrual disorders among university students in Turkey. Pediatrics International, 2007, 49:938-942.

2. Goldrath $\mathrm{MH}$. Hysteroscopic endometrial ablation. Obstetrics and Gynecology Clinics of North America, 1995, 22:559-572.
3. Houston AM et al. Knowledge, attitudes, and consequences of menstrual health in urban adolescent females. Journal of Pediatric and Adolescent Gynecology, 2006, 19:271-275.

4. Bitzer J, Tschudin S, Stadlmayr W. Die Menstruation und ihre Bedeutung fur die Frauengesundheit. [Menstruation and its 
impact on women's health.]. Zentralblatt fur Gynakologie, 2005, 127:282-287.

5. Kadir RA, Edlund M, Von Mackensen S. The impact of menstrual disorders on quality of life in women with inherited bleeding disorders. Haemophilia, 2010, 6:832-839.

6. Howard WJ. Novak's text book of gynecology, 12th ed. Philadelphia, Williams and Wilkins, 1996.

7. Mahkam T et al. The prevalence of menstrual pain and associated risk factors among Iranian women. Journal of Obstetrics and Gynaecology Research, 2011, 37:442-451.

8. Lambert-Messerlian $G$ et al. First assessment of menstrual cycle function and reproductive endocrine status in Samoan women. Human Reproduction (Oxford, England), 2011, 26:2518-2524.

9. Glueck CJ et al. Sex hormone-binding globulin, oligomenorrhea, polycystic ovary syndrome, and childhood insulin at age 14 years predict metabolic syndrome and class III obesity at age 24 years. Journal of Pediatrics, 2011, 159:308-313.

10. Ibáñez L et al. Early metformin therapy (age 8-12 years) in girls with precocious pubarche to reduce hirsutism, androgen excess, and oligomenorrhea in adolescence. Journal of Clinical Endocrinology and Metabolism, 2011, 96:E1262-E1267.

11. Chang P-J et al. Risk factors on the menstrual cycle of healthy Taiwanese college nursing students. Australian and New Zealand Journal of Obstetrics and Gynaecology, 2009, 49:689-694.

12. Vyver E, Steinegger C, Katzman DK. Eating disorders and menstrual dysfunction in adolescents. Annals of the New York Academy of Sciences, 2008, 1135:253-264.

13. Fujiwara $T$, Nakata R. Skipping breakfast is associated with reproductive dysfunction in post-adolescent female college students. Appetite, 2010, 55:714-717.

14. Vyver E, Steinegger C, Katzman DK. Eating disorders and menstrual dysfunction in adolescents. Annals of the New York Academy of Sciences, 2008, 1135:253-264.

15. Mesaki $\mathrm{N}$ et al. [Menstrual characteristics in college athletes.]. Nippon Sanka Fujinka Gakkai Zasshi, 1984, 36:247-254 [in Japanese].

16. Ornstein RM, Copperman NM, Jacobson MS. Effect of weight loss on menstrual function in adolescents with polycystic ovary syndrome. Journal of Pediatric and Adolescent Gynecology, 2011, 24:161-165.

17. Allsworth JE et al. The influence of stress on the menstrual cycle among newly incarcerated women. Women's Health Issues, 2007, 17:202-209.

18. Lin H-T et al. The impact of self-perceived job stress on menstrual patterns among Taiwanese nurses. Industrial Health, 2007, 45:709-714.

19. Chhabra S, Venkatraman S. Menstrual dysfunction in rural young women and the presence of polycystic ovarian syndrome. Journal of the Institute of Obstetrics and Gynaecology, 2010, 30(1):41-45.

20. Gast GC et al. Menstrual cycle characteristics and risk of coronary heart disease and type 2 diabetes. Fertility and Sterility, 2010, 94:2379-2381.

21. Nonato DR et al. Menstrual disturbances in systemic lupus erythematosus patients using immunosuppressants. Revista Brasileira de Reumatologia, 2010, 50:501-515.

22. Bauer J, Cooper-Mahkorn D. Reproductive dysfunction in women with epilepsy: menstrual cycle abnormalities, fertility, and polycystic ovary syndrome. International Review of Neurobiology, 2008, 83:135-155.

23. Adachi T. [Anemia in the field of obstetrics and gynecology]. Japanese Journal of Clinical Medicine, 2008, 66:548-552 [in Japanese].

24. Carlson KJ, Eisenstat SA, Ziporyn T. The new Harvard guide to women's health. Harvard, Massachusetts, Harvard University Press, 2004:384.

25. Toaff R, Ballas S. Traumatic hypomenorrhea-amenorrhea (Asherman's syndrome). Fertility and Sterility, 1978, 30:379-387.

26. Practice guidelines. Jackson, Mississippi, University of Mississippi Medical Center, Department of Obstetrics and Gynecology, 2002.

27. Palep-Singh $\mathrm{M}$, Prentice A. Epidemiology of abnormal uterine bleeding. Best Practice \& Research. Clinical Obstetrics \& Gynaecology, 2007, 21:887-890.

28. Walraven G et al. Menstrual disorders in rural Gambia. Studies in Family Planning, 2002, 33:261-268.

29. Harlow SD, Campbell OMR. Menstrual dysfunction: a missed opportunity for improving reproductive health in developing countries. Reproductive Health Matters, 2000, 8:142-147.

30. Andersch B, Milsom J. An epidemiologic study of young women with dysmenorrhea. American Journal of Obstetrics and Gynecology, 1982, 144:655-660.

31. Dickerson LM, Mazyck PJ, Hunter MH. Premenstrual synz drome. American Family Physician, 2003, 67:1743-1752.

32. Bloch M, Schmidt PJ, Rubinow DR. Premenstrual syndrome: evidence for symptom stability across cycles. American Journal of Psychiatry, 1997, 154:1741-1746.

33. Wilson C, Keye W. A survey of adolescent dysmenorrhea and premenstrual symptom frequency. Journal of Adolescent Health Care, 1989, 10:317-322.

34. Flug D, Largo RH, Prader A. Menstrual patterns in adolescent Swiss girls: a longitudinal study. Annals of Human Biology, 1984, 11:495-508.

35. Dawood MY. Dysmenorrhea. Clinical Obstetrics and Gynecology, 1990, 33:168-178.

36. Lee LK et al. Menstruation among adolescent girls in Malaysia: a cross-sectional school survey. Singapore Medical Journal, 2006, 47:869-874.

37. Allsworth JE et al. The influence of stress on the menstrual cycle among newly incarcerated women. Women's Health Issues, 2007, 17(4):202-209.

38. Anandha Lakshmi S et al. Prevalence of premenstrual syndrome and dysmenorrhoea among female medical students and its association with college absenteeism. International Journal of Biological and Medical Research, 2011, 2:1011-1016.

39. Parente Barbosa $\mathrm{C}$ et al. The effect of hormones on endomee triosis development. Minerva Ginecologica, 2011, 63:375-386.

40. Flick BM et al. Associations between psychiatric disorders and menstrual cycle characteristics. Archives of Psychiatric Nursing, 2008, 22:254-265.

41. Lentz GM. Abnormal uterine bleeding. In: Katz $\mathrm{V}$ et al, eds. Comprehensive gynecology, 5th ed. Philadelphia, Mosby, 2007:915-932.

42. Yonkers KA, O'Brein PMS, Eriksson E. Premenstrual syndrome. Lancet, 2008, 371:1200-1210. 